\title{
GRUPOS DE PESQUISAS E ENFOQUE DADO AO LAZER DAS PESSOAS COM DEFICIÊNCIA NA PRODUÇÃO CIENTÍFICA NO BRASIL
}

\author{
Recebido em: 04/08/2013
}

Aceito em: 12/04/2014

\author{
Junior Vagner Pereira da Silva ${ }^{1}$ \\ Universidade Federal do Mato Grosso do Sul \\ Campo Grande - MS - Brasil \\ Tattiana Côrtes Farias de Mendonça ${ }^{2}$ \\ Universidade Estadual de Santa Cruz \\ Ilhéus - BA - Brasil \\ Tânia Mara Vieira Sampaio ${ }^{3}$ \\ Universidade Católica de Brasília \\ Brasília - DF - Brasil
}

RESUMO: A investigação tem como objetivo mapear os grupos de pesquisas sobre o lazer no Brasil e analisar o enfoque dado ao lazer das pessoas com deficiência na produção científica. Caracterizada como fase exploratória da tese de doutoramento do primeiro autor, o estudo se constituiu em pesquisa documental, com abordagem qualitativa e quantitativa. $\mathrm{O}$ objeto das análises foram os grupos de pesquisas sobre lazer cadastrados no Diretório dos Grupos de Pesquisas no Brasil e o Currículo Lattes dos líderes. Os resultados indicam a existência de 73 grupos de pesquisas específicos e 92 não específicos. Em relação ao perfil demográfico, tanto para os grupos específicos quanto para os não específicos, a maioria está localizada na região Sudeste; os líderes são doutores e estão vinculados a Universidades Públicas, têm a divulgação do conhecimento produzido predominantemente em periódicos e possuem experiência em orientações de iniciação científica e mestrado. Quanto aos enfoques dados aos estudos do lazer das pessoas com deficiência, apenas três grupos específicos e sete não específicos têm pelo menos uma linha de pesquisa que aborda esta problemática, condição que pode ter contribuído com a inexpressível quantidade de publicações (em periódicos e em livros) e orientações (iniciação científica, mestrado e doutorado) que abordem temáticas sobre o lazer desta população. Conclui-se que a produção do conhecimento em lazer se encontra centralizada, o que resulta em prejuízos ao desenvolvimento político e cultural das demais regiões e que as investigações sobre o lazer das pessoas com deficiência são raras e demandam maior investimento dos estudiosos do lazer.

PALAVRAS CHAVE: Conhecimento. Atividades de Lazer. Pessoas com Deficiência. Grupos de Pesquisa.

\footnotetext{
${ }^{1}$ Doutor em Educação Física pela Universidade Católica de Brasília; Docente no curso de Educação Física da Universidade Federal do Mato Grosso do Sul.

${ }^{2}$ Formanda em Educação Física pela Universidade Estadual de Santa Cruz - UESC.

${ }^{3}$ Doutora em Ciência da Religião, Docente no programa de Graduação e Pós-graduação (Mestrado e Doutorado) na Universidade Católica de Brasília.
} 


\section{RESEARCH FOCUS GROUPS AND GIVEN THE LEISURE OF PERSON WITH DISABILITIES IN SCIENTIFIC PRODUCTION IN BRAZIL}

ABSTRACT: The research aims to map groups of research on leisure in Brazil and analyze the focus given to leisure for people with disabilities in scientific production. Characterized as exploratory phase of the doctoral thesis of the first author of the study consisted, was formed in documentary research, with qualitative and quantitative approach. The object of the analysis were the groups of research on leisure registered in the Directory of Research Groups in Brazil and Lattes leaders. The results indicate the existence of 73 research groups and 92 specific non-specific. Regarding the demographic profile, both for specific groups and for the non-specific, most are located in the Southeast; leaders are doctors and are linked to public universities, the dissemination of knowledge have produced predominantly in journals and have experience in guidance undergraduates and masters. Regarding the approaches given to leisure studies of people with disabilities, only three specific groups and seven did not have at least one specific line of research that addresses this problem, a condition that may have contributed to the inexpressible amount of publications (in journals and books ) and guidelines (scientific initiation, master's and doctoral) to address issues about the pleasure of this population. We conclude that the production of knowledge in leisure is centralized, which results in damage to the political and cultural development of other regions and that the investigation into the leisure of people with disabilities are rare and require greater investment of leisure scholars.

KEYWORDS: Knowledge. Leisure Activities. Research Groups. Disabled Persons.

\section{INTRODUÇÃO}

Ao longo da história, diferentes foram os conhecimentos usados para explicar as indagações humanas, todavia, é o conhecimento científico que, a partir dos últimos séculos, tem desfrutado de maior prestígio, haja vista que pautado em rituais e rigores reconhecidos em geral como importantes se firmou como explicação dominante e intelectualmente mais aceita, ou seja, um conjunto de cuidados que, se seguidos, tendem a assegurar maior aproximação à realidade.

Independente da concepção filosófica que norteie o pensamento científico entende-se que a produção do conhecimento ocorre por intermédio da pesquisa, atividade básica da ciência e razão fundante da vida acadêmica (DEMO, 2011). Por conseguinte, dentre as diferentes etapas que configuram o processo de desenvolvimento do estudo científico, encontra-se a fase exploratória, que se dedica a indagar, preliminarmente, um determinado objeto de pesquisa, assim como analisar a produção científica e os pressupostos 
Junior Vagner P. da Silva, Tatiana C. Farias de Mendonça e Grupos de Pesquisa e Enfoque dado ao Lazer... Tânia Mara Vieira Sampaio

epistemológicos que norteiam a construção do conhecimento em uma área específica de interesse (MINAYO, 1994), caracterizando-se como uma das mais importantes etapas, haja vista que auxilia na escolha do objeto de estudo, delimitação e definição do problema, objetivos e marco teórico que subsidiarão a investigação (DESLANDES, 1994).

Dentre as possibilidades de conhecimento sobre o estágio e desenvolvimento de uma determinada área ou assunto, destaca-se o exercício acadêmico de análise do "estado da arte", que consiste na avaliação de produções científicas, como livros, teses, dissertações, artigos, trabalhos publicados em eventos, resumos em anais, dentre outras fontes bibliográficas ou documentais, sobre o qual se pretende lançar novos olhares, sendo esta etapa de grande relevância, pois conforme expõe Peixoto (2008) não se pode avançar o campo do conhecimento quando se desconhece o estágio de seu andamento.

Todo e qualquer trabalho acadêmico, independente do tema ou dos objetivos perseguidos, carece do levantamento do conhecimento da produção préexistente. Chama-se a isso de levantamento do estado da arte - cuja finalidade é reconhecer os avanços e limites de um determinado tema de estudo. É este conhecimento do estado da arte que permite a identificação de problemáticas significativas para a pesquisa e a ampliação dos conhecimentos em dado campo (PEIXOTO, 2007, p. 562).

Dito de outra forma, se pode afirmar que este tipo de análise é uma importante estratégia para o delineamento do objeto de investigação, pois possibilita a projeção de luz sobre diferentes pontos de vistas a respeito (MINAYO, 2004).

No que tange à produção do conhecimento a respeito do lazer no Brasil, segundo Peixoto (2007), ela se encontra temporalmente organizada em quatro ciclos. Tendo como referência o período de 1930 a 1960. O primeiro ciclo se caracteriza por estudos relacionados à política de ocupação do tempo livre das crianças, organização e disseminação de jogos, brinquedos e brincadeiras e o uso da recreação na produtividade. O segundo ciclo se dá com o aprimoramento teórico/conceitual e ampliação de estudos empíricos entre 1960 a 1980, com ascensão na década de 1970, através da criação do Centro de Estudos do Lazer (CELAR), 
Junior Vagner P. da Silva, Tatiana C. Farias de Mendonça e Grupos de Pesquisa e Enfoque dado ao Lazer... Tânia Mara Vieira Sampaio

realização do I Encontro Estadual sobre Lazer/1974 e o primeiro curso de Especialização em Lazer do país/1975 pela Pontifícia Universidade Católica (PUC) de Porto Alegre e diversas iniciativas do Serviço Social do Comercio (SESC) - prestação de serviços em lazer, estruturação do Centro de Estudos do Lazer e da Recriação (CELAZER), editoração de livros, organização de eventos científicos (I Encontro Estadual sobre lazer - PUC/1974, I Encontro Nacional de Recreação em 1976; I Encontro Nacional sobre o Lazer e Cultura em 1995). Por seu turno, o terceiro ciclo ocorre com as primeiras iniciativas de abordagem do lazer como temática da pós-graduação (Especialização em lazer pela Unicamp em 1991), realização do I Encontro Nacional de Profissionais de Recreação e Lazer - Brasília/1989 ${ }^{4}$, primeiras edições do Seminário Lazer em Debate (CELAR) Universidade Federal de Minas Gerais (UFMG/2000), criação da primeira revista especializada em lazer - Licere/1998; ; dando início ao ciclo de elaboração de estudos relacionados à crítica da produção científica e natureza ideológica dos estudos do lazer. Pautado, sobretudo na produtividade, o quarto ciclo se inicia no final da década de 90, resultando na elevação do número dos grupos de pesquisas e publicações na área.

Em consequência do aumento de estudos sobre o lazer no final da década 90, a partir de 2000 pesquisas do tipo "estado da arte" começam a ser desenvolvidas, destacando-se entre os objetivos a(s) análise(s) da(o)s: trajetória dos estudos e grupos de pesquisas sobre o lazer no Brasil (GOMES; MELO, 2003); mapeamento da produção científica referente aos estudos do lazer no Brasil nos séculos XX a XXI (PEIXOTO, 2007); apropriação da obra de Marx e Engels nos estudos do lazer (PEIXOTO, 2008), encaminhamentos dados sobre as temáticas lazer e políticas públicas (MARCELLINO et al., 2009); dimensões da política pública e

\footnotetext{
${ }^{4}$ O ENAREL - Encontro Nacional de Recreação e Lazer, nome dado ao evento a partir de 1991, configura-se no maior evento e um dos principais canais de veiculação do conhecimento nacional sobre o lazer no país. Para maiores informações sobre a história deste evento ler (MARCELLINO, Nelson Carvalho; ISAYAMA, Hélder Ferreira. ENAREL: 21 anos de história. Brasília: Supernova Gráfica, 2010. Disponível em: http://www.esporte.gov.br/arquivos/sndel/esporteLazer/cedes/afLivroEnarelDigital.pdf).

5 Criada em 1998, a revista Licere, atualmente classificada no Qualis/CAPES no extrato B2, constitui-se como única revista específica em estudos do lazer do país.
} 
Junior Vagner P. da Silva, Tatiana C. Farias de Mendonça e Grupos de Pesquisa e Enfoque dado ao Lazer... Tânia Mara Vieira Sampaio

tratado metodológico adotados nas investigações (AMARAL; PEREIRA, 2009); formação e atuação profissional (STOPPA et al., 2010); temáticas predominantes e autores relacionados aos estudos do lazer no período de 1891-1969 (PEIXOTO; PEIREIRA, 2010), lazer e políticas públicas no setor governamental (ALVES et al., 2011); lazer e intercâmbio internacional (MARINHO et al., 2011); lazer e políticas públicas no ambiente não governamental - terceiro setor e clubes (ALVES et al., 2012); formação profissional em lazer (FERREIRA; SILVA, 2012) e políticas públicas sociais de esporte e lazer (CASTRO et al., 2012).

Ao passo que os estudos disponíveis na literatura sobre o "estado da arte" do lazer demonstram ter contribuído significativamente para melhor entendimento das questões e temáticas às quais se propuseram, ao analisá-los verifica-se a existência de limitações e lacunas, abrindo espaços para que novos olhares sejam lançados aos trabalhos relacionados ao lazer.

Uma das limitações evidenciadas é que os estudos vêm se pautando tão somente por um dos interesses culturais, o físico/esportivo - e apenas a produção científica de uma área do conhecimento, a Educação Física, fazendo com que inexistam dados a respeito do mapeamento de pesquisas sobre os demais interesses culturais e as diversas áreas que estudam o lazer. Este fator dificulta (quando não limita) a compreensão deste fenômeno, pois a partir da década de 1970 o lazer passou a ser entendido como uma área multidisciplinar, abrangendo temas, discussões, projetos e pesquisas coordenados por pesquisadores das mais diferentes áreas do conhecimento - Educação Física, Pedagogia, Administração, Economia, Arquitetura e Urbanismo, Psicologia, Sociologia, Antropologia (GOMES; MELO, 2003; PEIXOTO, 2007), Terapia Ocupacional (GOMES; MELO, 2003), Filosofia, História, Geografia, Matemática, Enfermagem, Turismo e Hotelaria (PEIXOTO, 2007). 
Junior Vagner P. da Silva, Tatiana C. Farias de Mendonça e Grupos de Pesquisa e Enfoque dado ao Lazer... Tânia Mara Vieira Sampaio

Outra lacuna observada é a ausência de levantamentos que tenham levado em consideração populações específicas, como as pessoas com deficiências, dificultando a compreensão das questões relativas ao lazer desta população e aos diferentes conteúdos culturais que o compõe, pois o único disponível na literatura com este delineamento (MUNSTER; ROSSI; FERREIRA, 2012) se limitou a avaliar os grupos de pesquisas e as produções relativas ao esporte adaptado, que, embora importante, se mostra insuficiente para compreendermos as questões que envolvem essa população e o lazer em suas diferentes manifestações culturais - artísticas, esportivas, sociais, intelectuais, manuais e turísticas.

Isso posto, a presente investigação tem como objetivo mapear os grupos de pesquisas sobre o lazer no Brasil e analisar o enfoque dado ao lazer das pessoas com deficiência na produção científica. Especificamente, mapeia o perfil demográfico dos grupos de pesquisas sobre o lazer no Brasil (grupos cadastrados, grandes áreas e áreas que se encontram vinculados, ano de formação, localização geográfica, titulação dos líderes e status jurídico das instituições); investiga as temáticas de interesse das linhas de pesquisas vinculadas aos grupos, avalia as temáticas abordadas nas publicações (artigos em periódicos, livros e capítulos de livros) e orientações (iniciação científica, mestrado e doutorado) dos líderes dos grupos e o enfoque dado ao lazer das pessoas com deficiência.

\section{PROCEDIMENTOS METODOLÓGICOS}

O trabalho se configura como fase exploratória da tese de doutoramento "Parques esportivos como espaço e lugar de in(ex)clusão de pessoa com deficiência física e visual”“

Quanto ao delineamento, o estudo é do tipo documental, com análise de dados secundários (GIL, 2010). A fonte documental secundária, objeto de análise, foi a plataforma on-line de integração de bases de dados de Currículos, Grupos de pesquisa e de Instituições -

\footnotetext{
6 Trabalho desenvolvido pelo primeiro autor junto ao Programa de Pós-graduação Stricto Sensu (Mestrado/Doutorado) em Educação Física da Universidade Católica de Brasília (UCB).
} 
Junior Vagner P. da Silva, Tatiana C. Farias de Mendonça e Grupos de Pesquisa e Enfoque dado ao Lazer... Tânia Mara Vieira Sampaio

Plataforma Lattes (http://lattes.cnpq.br/) vinculada ao Conselho Nacional de Desenvolvimento Científico e Tecnológico (CNPq), especificamente, a base dos Diretórios dos Grupos de Pesquisas no Brasil (http://dgp.cnpq.br/buscaoperacional/) e dos Currículos Lattes dos líderes $\operatorname{dos}$ grupos de pesquisas (http://buscatextual.cnpq.br/buscatextual/busca.do?metodo=apresentar), sendo que as buscas foram realizadas em fevereiro de 2013.

O Diretório dos Grupos de Pesquisa no Brasil, fundado em 1992, se constitui em um inventário no qual são registradas e unificadas as informações decorrentes da pesquisa no país - grupos e linhas de pesquisas (especificidade do conhecimento; produção científica, tecnológica e artística; recursos humanos envolvidos - pesquisadores, acadêmico e técnicos -; localização geográfica; origem dos grupos - público ou privada), dentre outras informações. Por seu turno, o Currículo Lattes é base padrão nacional de registro da vida profissional e acadêmica de pesquisadores e estudantes no país, constituindo-se em fonte de análise de mérito em editais de concursos públicos, fomento a pesquisas, seleção de pós-graduações, bolsas de pesquisas, dentre outros processos.

Para identificação dos grupos de pesquisas cadastrados no Diretório, realizamos as buscas com filtragens em dois níveis: a) Filtragem simples - por grande área, objetivando identificar a grande área em que os grupos de estudos estão vinculados e, b) Filtragem combinada - por grande área do grupo e por área do grupo, utilizando nas buscas os descritores lazer, recreação, ócio e tempo livre, considerando que estes termos são usados na produção de conhecimento, por vezes, como sinônimos (MARCASSA, 2002; PEIXOTO, 2007).

As palavras-chave, pelas quais os grupos de pesquisas são identificados, são determinadas e registradas pelo líder ao efetuar o cadastro no Diretório e que, mesmo cadastrando uma dada palavra-chave, o grupo pode abordar as questões relacionadas a esta 
Junior Vagner P. da Silva, Tatiana C. Farias de Mendonça e Grupos de Pesquisa e Enfoque dado ao Lazer... Tânia Mara Vieira Sampaio

apenas ocasionalmente, ou seja, o foco principal não é um determinado tema, como, por exemplo, o lazer, conforme constatado nos estudos de Gomes e Melo (2003). Após procedermos à identificação dos grupos, realizamos uma segunda filtragem e refinamento através da análise da presença de um dos quatro unitermos (lazer, recreação, ócio ou tempo livre) no título ou nas palavras-chave usadas pelas linhas de pesquisas vinculadas ao grupo ou vínculo dos objetivos da linha de pesquisa a um ou mais interesses culturais.

A partir desta primeira análise, os grupos foram classificados em três: excluídos (identificados por meio das palavras-chave, porém não apresentavam um dos unitermos no título das linhas de pesquisa, nas palavras-chave ou não demonstravam vínculo aos estudos do lazer nos objetivos); não específicos (embora identificados por um dos unitermos no título da linha de pesquisa, nas palavras-chave ou demonstravam vínculo aos estudos do lazer nos objetivos, a quantidade de linhas relacionadas ao lazer eram inferiores a $51 \%$ da quantidade total de linhas cadastradas no grupo); específicos (identificados por um dos unitermos no título da linha de pesquisa, nas palavras-chave ou demonstraram ter vínculos aos estudos do lazer nos objetivos e que a quantidade de linhas relacionadas ao lazer eram superiores a $51 \%$ do total de linhas cadastradas no grupo).

Como critérios de exclusão, adotou-se a desatualização do grupo no Diretório do CNPq por mais de 12 meses e a ausência de pelo menos uma linha de pesquisa relacionada aos estudos do lazer. Como critérios de inclusão, a identificação de um dos unitermos utilizados (lazer, recreação, ócio ou tempo livre) no título das linhas de pesquisas, nas palavras-chave ou objetivos das linhas de pesquisas relacionados aos interesses culturais do lazer.

Posteriormente, procedeu-se a análise de cada um dos Grupos de Pesquisas classificados como específicos e não específicos, extraindo das páginas as seguintes informações: nome do grupo, nome do líder, grande área e área do conhecimento que se 
Junior Vagner P. da Silva, Tatiana C. Farias de Mendonça e Grupos de Pesquisa e Enfoque dado ao Lazer... Tânia Mara Vieira Sampaio

encontram vinculados, localização geográfica, titulação do líder, status jurídico, produção científica (artigos publicados, artigos aceitos para publicação, livros publicados e/ou organizados, e capítulos de livros publicados) e orientações científicas (iniciação científica, mestrado e doutorado).

A etapa subsequente consistiu na avaliação das temáticas objeto de investigação de cada uma das linhas de pesquisas. Para proceder à identificação das temáticas abordadas, recorremos à técnica de análise de conteúdo (BARDIN, 2009), mais especificamente a técnica de análise temática, que se traduz na identificação de núcleos de sentido (MINAYO, 2004) ou conforme expõe Bardin (2009, p. 105) é a "“[...] unidade de significação que se liberta naturalmente de um texto analisado segundo critérios relativos à teoria que serve de guia à leitura", podendo ser apresentada por uma palavra, uma frase, um resumo.

Sua aplicação ocorreu em três etapas: pré-análise - organização do material (leitura preliminar dos objetivos de cada uma das linhas de pesquisa); exploração do material codificação (transformação dos dados brutos e recorte do texto em unidades menores, temáticas), determinação das regras de contagem (quantificação) e classificação (classificação e agrupamento das informações por categorias teóricas ou empíricas, temáticas) e interpretação inferencial (análise de frequência e interpretação teórica a fim de descobrir tendências) (BARDIN, 2009).

Para análise da produção de conhecimento e orientações acadêmicas adotou-se as produções desenvolvidas pelo primeiro líder de cada grupo, estratégia metodológica que tem sido utilizada em estudos disponíveis na literatura (DUCA et al., 2011; BORGES et al., 2012; SANTOS et al., 2012). Optou-se por essa análise devido à inviabilidade de avaliar as publicações científicas por meio do Currículo Lattes de todos os pesquisadores que apresentaram vínculo e desenvolvem estudos sobre o lazer. Ademais, a análise do currículo Lattes de todos os pesquisadores vinculados às linhas de pesquisas seria muito moroso, 
Junior Vagner P. da Silva, Tatiana C. Farias de Mendonça e Grupos de Pesquisa e Enfoque dado ao Lazer... Tânia Mara Vieira Sampaio

devido à necessidade de efetuar a filtragem dos artigos publicados em autoria e coautoria para que não houvesse sobreposição no cômputo.

A partir da identificação dos grupos de pesquisas que desenvolvem estudos sobre o lazer, procedemos a análise da produção científica dos líderes (artigos publicados, artigos aceitos para publicação, capítulos de livros e livros publicados) e trabalhos orientados em nível de iniciação científica, mestrado e doutorado e as temáticas abordadas nos estudos. Uma vez diagnosticados todos os aspectos relacionados ao lazer, uma segunda filtragem e análise foi realizada no currículo de cada líder, buscando identificar as produções científicas e orientações acadêmicas relacionadas ao lazer das pessoas com deficiência.

A exemplo da técnica de investigação utilizada na análise das temáticas abordadas pelas linhas de pesquisas, para avaliação da produção de conhecimento, orientações acadêmicas e questões relativas ao lazer das pessoas com deficiência, recorremos também a análise de conteúdo (BARDIN, 2009).

\section{RESULTADOS E DISCUSSÃO}

Os resultados indicam que atualmente existem 256 grupos relacionados com as palavras-chave lazer, ócio, recreação e/ou tempo livre cadastrados no Diretório de Pesquisa do CNPq. Entretanto, destes, 91 se enquadraram nos critérios de exclusão, sendo 32 descartados por estarem desatualizados a mais de 12 meses e 59 por não terem nenhuma linha de pesquisa relacionada aos estudos do lazer. Dos 165 grupos que atenderam aos critérios de inclusão, 73 foram classificados como específicos e 92 como não específicos.

Quando comparada a investigações anteriores, nota-se que a quantidade de grupos de pesquisas relacionados ao lazer cadastrados atualmente no Diretório de Grupos de Pesquisa no Brasil é superior aos identificados por Gomes e Melo (2003) - 51 grupos, e inferior aos obtidos por Marinho et al. (2011) - 211 grupos. 
Junior Vagner P. da Silva, Tatiana C. Farias de Mendonça e Grupos de Pesquisa e Enfoque dado ao Lazer... Tânia Mara Vieira Sampaio

A discrepância observada em relação ao estudo desenvolvido por Gomes e Melo (2003) pode estar relacionada, sobretudo, ao aumento do número de pesquisadores interessados em estudar o lazer nos últimos dez anos. Já a diferença em relação aos grupos identificados por Marinho et al. (2011) pode ser decorrente da não utilização de filtros no desenvolvimento da pesquisa realizada pelas autoras. Contudo, não se descarta que as diferenças dos achados dos dois estudos em relação aos dados obtidos na presente investigação também estejam relacionadas a questões metodológicas, uma vez que em Gomes e Melo (2003) não se sabe a metodologia aplicada na classificação dos grupos como oriundos do lazer, pois os autores não apresentam nenhuma informação a respeito (descritores, filtragem, critérios de inclusão e exclusão adotados), condição similar diagnosticada no trabalho de Marinho et al. (2011), que se limitou a informar o uso de apenas uma palavrachave, nada informando sobre o tipo de filtragem ou análise crítica, o que sugere, pela quantidade de grupos identificados, a classificação dos grupos como de lazer tão somente a partir das palavras-chave, o que não representa a realidade, haja vista que, conforme observado em nossas buscas, embora identificados com as palavras-chave, após análise, 59 grupos mostraram-se não ter qualquer relação com o lazer.

As Ciências da Saúde e Ciências Sociais e Aplicadas (entre os grupos específicos) e as Ciências da Saúde e Ciências Humanas (entre os não específicos) se configuram como as grandes áreas em que se encontram mais grupos de estudos do lazer, sobretudo, as Ciências da Saúde, que apresenta uma diferença substancial quando comparada às demais.

Ao proceder à análise por áreas, verifica-se que a Educação Física tanto nos grupos específicos quanto nos não específicos, o Turismo nos específicos e a Educação entre os não específicas, se constituem nas que mais grupos de estudos apresentam. Todavia, nota-se que até mesmo entre esses há uma elevada discrepância, pois a quantidade de grupos específicos 
Junior Vagner P. da Silva, Tatiana C. Farias de Mendonça e Grupos de Pesquisa e Enfoque dado ao Lazer... Tânia Mara Vieira Sampaio

vinculados a Educação Física é o dobro em relação aos do Turismo e a quantidade de grupos não específicos vinculados a Educação Física o triplo daqueles vinculados a Educação.

A sobreposição da Educação Física nos estudos e publicações sobre o lazer também tem sido observada em outras investigações. Tomando como base de análise os trabalhos publicados nos anais do Encontro Nacional de Recreação e Lazer (ENAREL) entre 1991 e 2008, embora tenham constatado a participação e a existência de produções relacionadas a outras áreas - Gestão, Assistência Social, Paisagismo, Fotografia, Pedagogia, Biblioteconomia-, Marcellino et al. (2009) evidenciaram que a maioria dos estudos estavam relacionados ao interesse físico-esportivo, assim como a maioria dos participantes eram profissionais formados em Educação Física. Posição similar foi observada por Alves et al. (2011) ao investigarem as produções científicas publicadas na revista Licere, demonstrando que, em que pese a multidisciplinariedade do lazer, objeto de estudo que comporta diversas áreas, quando comparadas à Educação Física, a participação das demais áreas em grupos de pesquisas e publicações sobre o lazer ainda se mostra tímida. 
Junior Vagner P. da Silva, Tatiana C. Farias de Mendonça e Grupos de Pesquisa e Enfoque dado ao Lazer... Tânia Mara Vieira Sampaio

Tabela 1 Distribuição dos grupos de pesquisas sobre o lazer cadastrados no Diretório de Grupos de Pesquisas no Brasil - grandes áreas e áreas de conhecimento

\begin{tabular}{|c|c|c|c|}
\hline & & Grupos de & esquisas \\
\hline GRANDES ÁREAS & ÁREAS & Específicos & Não específicos \\
\hline Ciências da Saúde & & & \\
\hline & Educação Física & 36 & 45 \\
\hline & Enfermagem & - & 1 \\
\hline & Fisioterapia e Teoria Ocupacional & - & 1 \\
\hline & Medicina & - & - \\
\hline & Nutrição & - & 1 \\
\hline & Saúde Coletiva & - & 1 \\
\hline Total & & 36 & 49 \\
\hline Ciências Humanas & & & \\
\hline & Antropologia & - & 3 \\
\hline & Educação & 8 & 13 \\
\hline & Geografia & 2 & - \\
\hline & História & 1 & 1 \\
\hline & Psicologia & 2 & 4 \\
\hline & Sociologia & 3 & 4 \\
\hline Total & & 16 & 25 \\
\hline Ciências Sociais e Aplicadas & & & \\
\hline & Administração & 1 & 4 \\
\hline & Arquitetura e urbanismo & - & 2 \\
\hline & Desenho Industrial & - & 1 \\
\hline & Planejamento urbano e regional & 1 & 3 \\
\hline & Turismo & 18 & 5 \\
\hline Total & & 20 & 15 \\
\hline Engenharias & & & \\
\hline & Engenharia da Produção & - & 2 \\
\hline Total & & - & 2 \\
\hline Linguística, Letras e Artes & & & \\
\hline & Artes & 1 & 1 \\
\hline Total & & 1 & 1 \\
\hline TOTAL & & 73 & 92 \\
\hline
\end{tabular}

A predominância da Educação Física em relação às demais áreas pode estar relacionada a associação historicamente construída entre lazer e atividades físicas esportivas (ISAYAMA, 2009) e maior exploração comercial de eventos esportivos pela mídia e, consequentemente, sua divulgação, fazendo com que, por vezes, seja percebida de forma restrita, reduzindo o lazer aos esportes/exercícios físicos (MELO; ALVES JÚNIOR, 2003; MARCELLINO, 2008). Todavia, essa condição parece se dar sobretudo pela inserção da recreação na matriz curricular dos cursos de nível superior em Educação Física desde a década de 1960 (PINTO, 1992), pelo destaque dado ao desporto enquanto direito constitucional em 1988 (MARCELLINO, 2008) e pelo preconceito sociológico que ainda 
Junior Vagner P. da Silva, Tatiana C. Farias de Mendonça e Grupos de Pesquisa e Enfoque dado ao Lazer... Tânia Mara Vieira Sampaio

permeia algumas áreas, como as Ciências Sociais, que ignorando o tema enquanto importante indicador social, persiste em não incluir o lazer em sua matriz curricular (PADILHA, 2006).

Quanto à localização e distribuição geográfica dos grupos, a Figura 1 demonstra que a maioria dos grupos específicos se encontra no Sudeste do país, condição não evidenciada entre os não específicos, que apresentaram percentuais idênticos nas regiões Sudeste e Nordeste e próximos aos do Sul. Por seu turno, os Estados com maior número de grupos de pesquisas específicos do lazer foram São Paulo, Rio de Janeiro e Minas Gerais e entre os não específicos Paraná, Minas Gerais e Bahia.

Figura 1. Distribuição geográfica dos grupos de pesquisas específicos e não específicos do lazer no Brasil
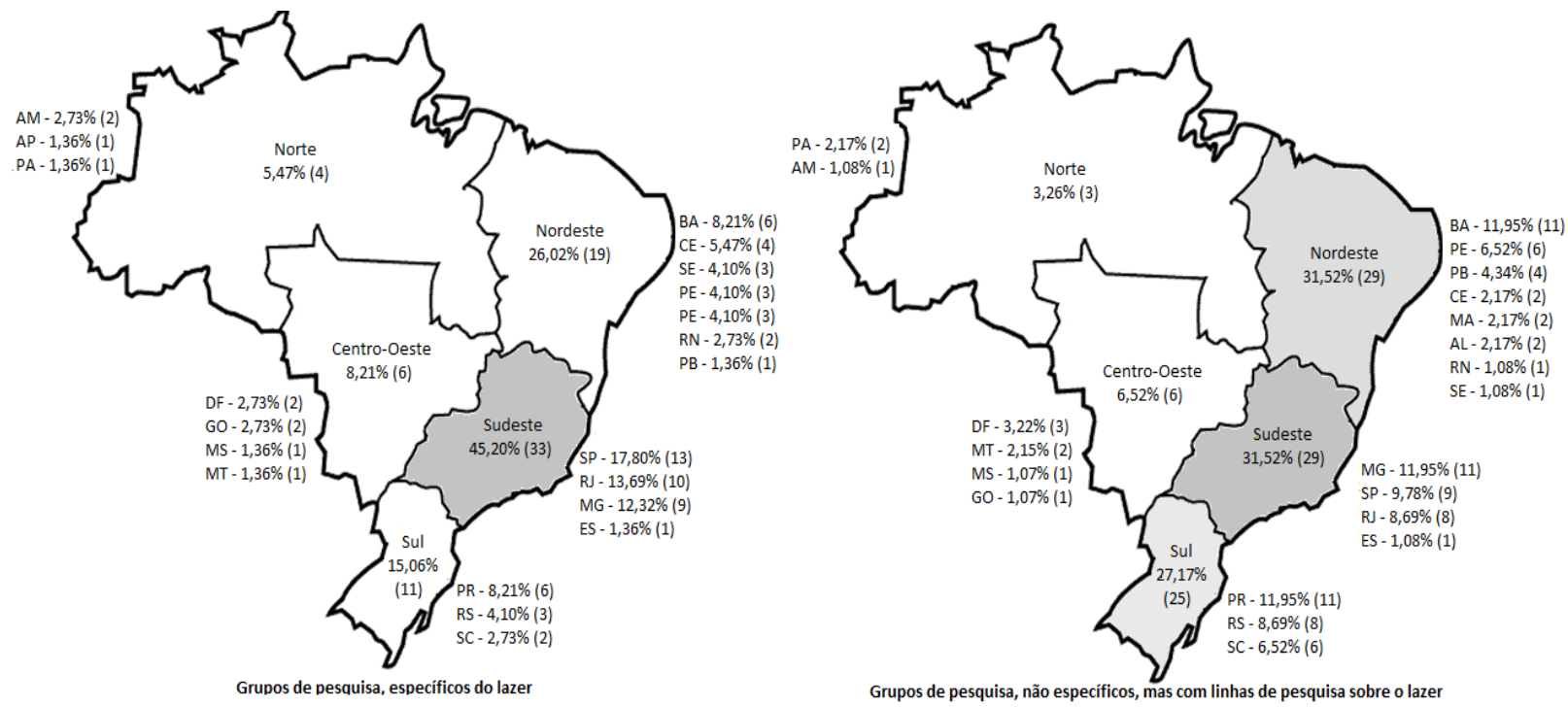

A predominância dos grupos de pesquisas específicos na região Sudeste pode estar relacionada aos desequilíbrios econômicos e políticos existentes em nosso país, pois desde o início do século $\mathrm{XX}$, o Sudeste se constitui palco do desenvolvimento político (Rio de Janeiro, primeira capital do país) e da industrialização (São Paulo). Desta forma, espaço fundamental da política e economia do país, historicamente esta região também tem se 
Junior Vagner P. da Silva, Tatiana C. Farias de Mendonça e Grupos de Pesquisa e Enfoque dado ao Lazer... Tânia Mara Vieira Sampaio

configurado na maior concentradora, dentre outros privilégios, de programas de pósgraduação Stricto Sensu - Mestrado, Doutorado e Mestrado profissional (GEOCAPES, 2013), condição que faz com que se sobreponha também em publicações (ZORZETTO et al., 2006) ${ }^{7}$, número de discentes, docentes e bolsas de fomento de pós-graduação Stricto Sensu (GEOCAPES, 2013), fazendo dela vitrine $\mathrm{e}$ atrativo, para que alunos e professores/pesquisadores busquem se vincular a instituições nela sediada, lá se instalando e formando grupos e redes. Esta condição tem resultado em significativos prejuízos à população das regiões com baixo desenvolvimento científico, considerando-se que a ciência e tecnologia são elementos relevantes para o desenvolvimento econômico e cultural, sendo assim necessário que sua distribuição ocorra de forma equilibrada e não como historicamente vem se constituindo.

Por outro lado, como explicar o Nordeste como segunda região com a maior quantidade de grupos específicos e a primeira, juntamente com o Sudeste, em grupos não específicos, condição contrária ao evidenciado no final do século XX, em que o Sul do país figurou como a segunda região mais desenvolvida em produção científica (MUGNAINI; JANNUZZI; QUONIAM, 2004) e em programas de pós-graduação (STEINER, 2005).

A explicação para a diminuição da assimetria entre grupos de pesquisas do Nordeste em relação às regiões Sudeste e Sul pode encontrar guarida em diversas ações do Governo Federal na última década, dentre elas: a) a ampliação da oferta da pós-graduação Stricto Sensu, pois conforme indicam os dados do Geocapes (2013), até 2004 a segunda maior região assistida por programas de Mestrado e Doutorado era o Sul, posição que em 2005 e 2006 começou a ser revertida e mantida em 2009, 2010 e 2011, quando o Nordeste passou a figurar como segunda região com maior número de programas; b) a reserva de, no mínimo, $30 \%$ dos

\footnotetext{
${ }^{7}$ Em estudo desenvolvido sobre os programas de pós-graduação (Mestrado e Doutorado) em Ciências Biológicas e da Saúde, os autores identificaram que das 20 Universidades brasileiras com maior publicação de artigos em periódicos identificados no ISI, doze eram da região Sudeste (USP, UFRJ, UNEFISP, USP-Ribeirão Preto, UNICAMP, FIOCRUZ, UFMG, UNESP-Botucatu, UERJ, UNESP-Rio Claro, UNICAMP-Piracicaba e UNESP-Araraquara) e três do Sul (UFRGS, UFPR, UFSC).
} 
Junior Vagner P. da Silva, Tatiana C. Farias de Mendonça e Grupos de Pesquisa e Enfoque dado ao Lazer... Tânia Mara Vieira Sampaio

recursos do Fundo Nacional de Desenvolvimento Científico e Tecnológico (FNDCT) investidos em pesquisas a serem desenvolvidas por Instituições sediadas nas regiões Norte, Nordeste e Centro-Oeste - Lei $\mathrm{n}^{\mathrm{o}} 10.197 / 2001$ (BRASIL, 2001 $^{\mathrm{a}}$ ); c) a reserva, a partir de 2006, de, no mínimo, de 30\% dos recursos destinados ao edital universal do Ministério da Ciência e Tecnologia e Inovação (MCTI)/CNPq a pesquisadores das regiões Nordeste, Norte e Centro-Oeste.

Todavia, em que pese às possíveis influências positivas destas mudanças na região Nordeste, cabe advertir que elas não eliminaram as discrepâncias existentes na educação e produção do conhecimento no país, pois o Centro-Oeste e o Norte ainda apresentam baixíssimos números de programas de pós-graduação e grupos de pesquisas, devendo novas estratégias ser pensadas a fim de proporcionar a ampliação da pesquisa nestas regiões grupos de pesquisas, pós-graduação Stricto Sensu, eventos científicos, dentre outros.

Isto indica que novos mecanismos de fomento e estimulação a organização de eventos, desenvolvimento de pesquisas e formação de grupos de estudos em regiões ainda carentes necessitam ser elaborados. Todavia, para tanto, no nosso entender, se faz relevante que a valorização e o investimento na ciência não ocorram tão somente enquanto componente da tecnologia pautados em interesses políticos/econômicos como visto no desenvolvimento tecnológico da indústria, gás natural e combustíveis, que são assegurados com repasses de percentuais dos valores nacionais ao Ministério de Ciência, Tecnologia e Informação (MCTI) para o fomento à realização de pesquisas - Lei $n^{0}$ 9.478/1997 (BRASIL, 1997). É fundamental que também sejam reservados e repassados recursos ao desenvolvimento de pesquisas e aprofundamento do conhecimento em áreas de saber relacionados às diferentes dimensões da vida, dentre elas, o lazer. Isto porque o único mecanismo de fomento específico que existia para esta área (advindo da Rede Centro de Desenvolvimento do Esporte Recreativo e do Lazer (Rede CEDES), vinculada a uma das Secretarias Nacionais do 
Junior Vagner P. da Silva, Tatiana C. Farias de Mendonça e Grupos de Pesquisa e Enfoque dado ao Lazer... Tânia Mara Vieira Sampaio

Ministério do Esporte) concedeu, nos primeiros anos (2003 a 2006), financiamentos por meio de convites diretos a grupos de pesquisas e, posteriormente, por meio de editais (2007 a 2011). No entanto, em 2012 criou-se um vazio de informações na relação Ministério do Esporte e grupos de pesquisas, pesquisadores e universidades, e os projetos aprovados no último edital de 2011 não foram contemplados com verbas. Isto ocorreu a despeito da abertura de edital - Portaria $n^{\circ}$ 179, de 20 de outubro de 2011 (BRASIL, 2011 ${ }^{\mathrm{a}}$ ) e avaliação/aprovação dos 42 projetos com méritos para o recebimento de recursos federais - Portaria $n^{\circ} 219$, de 23 de dezembro de 2011 (BRASIL, 2011b), sob a alegação de insuficiência de fundos, os valores antes aprovados e informados às universidades e pesquisadores não foram repassados pelo Ministério do Esporte, fazendo com que o investimento que já era insuficiente passasse a ser inexistente. Embora a Rede Cedes ainda exista na estrutura do Ministério do Esporte, os recursos e o sistema de financiamento de pesquisas foi extinto.

Necessário se faz ainda que editais de fomento para a organização de eventos, desenvolvimento de pesquisas, compra de equipamentos, dentre outros organizados pelo Ministério da Educação (MEC), MCTI, Coordenação de Aperfeiçoamento de Pessoal de Nível Superior (CAPES) e CNPq levem em consideração as particularidades e demandas existentes nas regiões do país, ou seja, que além de editais universais também lancem editais no formato indução de demanda a fim de incentivar a criação de grupos de pesquisas e desenvolvimento de estudos em regiões com pouco desenvolvimento e tradição em pesquisa, como o Norte e o Centro-Oeste, pois considerando que o Sudeste constitui-se na maior região concentradora de pesquisadores de ponta, maior quantidade de programas, discentes e bolsas de estudos do país, como já exposto neste trabalho, é razoável que já se saiba que a maioria dos pesquisadores contemplados também será do Sudeste, haja vista que o principal objeto de mérito dos editais destes órgãos de fomento tem sido as publicações em periódicos. Esta condição pode ser evidenciada nos resultados de editais do MCTI/CNPq e CAPES que não 
Junior Vagner P. da Silva, Tatiana C. Farias de Mendonça e Grupos de Pesquisa e Enfoque dado ao Lazer... Tânia Mara Vieira Sampaio

preveem a reserva de percentuais às regiões emergentes, como o edital no MCTI/CNPq/FINEP-ARC nº 06/2012 - Apoio à realização de eventos (CNPq, 2012), próequipamentos/CAPES (CAPES, 2012 ${ }^{\mathrm{a}}$ ) e professor visitante Sênior/CAPES (CAPES, 2012 ${ }^{\mathrm{b}}$ ), que indicam que os maiores contemplados/beneficiados foram as instituições e pesquisadores situados na região Sudeste.

Seguindo os mesmos caminhos da lei $\mathrm{n}^{0} 10.197 / 2001$ (BRASIL, 2001) e do edital universal CNPq se faz oportuno que os próximos editais de apoio a realização de eventos, pró-equipamentos, professor visitante, dentre outros, também estabeleçam a reserva de, no mínimo, 30\% dos recursos disponíveis às regiões Nordeste, Norte e Centro-Oeste. Outras estratégias, como a criação de editais de apoio à fixação de recursos humanos especificamente nas regiões Norte e Centro-Oeste, precisam ser pensadas, uma vez que ao passo que a região Nordeste tem apresentado avanços em diversos aspectos da pesquisa no cenário nacional, as medidas até então tomadas não foram suficientes para alavancar as pesquisas nestas duas regiões.

Ainda no que diz respeito ao perfil demográfico, a maioria dos grupos, tanto específicos como não específicos, é composta por líderes com a titulação de doutor, que se encontram vinculados a Instituições de Ensino Superior Públicas, tem os periódicos como seu principal veículo de circulação da produção de conhecimento e experiência na orientação de iniciação científica e mestrado. Contudo, apenas 30\% têm experiência na orientação em doutorado, conforme (TABELA 2). 
Junior Vagner P. da Silva, Tatiana C. Farias de Mendonça e Grupos de Pesquisa e Enfoque dado ao Lazer... Tânia Mara Vieira Sampaio

Tabela 2 Perfil demográfico dos líderes de grupos de pesquisas

\begin{tabular}{l|c|c}
\hline & \multicolumn{2}{c}{ Tipos de grupos } \\
\hline & $\begin{array}{r}\text { Grupos de pesquisa } \\
\text { específicos do lazer }\end{array}$ & $\begin{array}{r}\text { Grupos de pesquisa não } \\
\text { específicos do lazer }\end{array}$ \\
\hline TITULAÇÃO DOS LÍDERES & & \\
Doutor & 64 & 77 \\
Mestre & 8 & 13 \\
Especialista & 1 & 2 \\
STATUS JURÍDICO DAS IES & 63 & 80 \\
Pública & 10 & 10 \\
Particular & & 2 \\
Especial & & \\
PRODUÇÃO CIENTÍFICA & & 84 \\
Artigos em periódicos & 69 & 8 \\
Sim & 4 & 54 \\
Não & & 38 \\
Livros & 56 & 79 \\
Sim & 17 & 13 \\
Não & & \\
Capítulos de livros & 59 & 68 \\
Sim & 14 & 24 \\
Não & & 55 \\
ORIENTAÇÕES & & 37 \\
Iniciação científica & 55 & 34 \\
Sim & 18 & 58 \\
Não & & \\
Mestrado & 45 & \\
Sim & 28 & \\
Não & & \\
Doutorado & 26 & \\
Sim & 47 & \\
Não & & \\
\hline
\end{tabular}

A predominância de grupos de pesquisas vinculados a Instituições de Ensino Superior Públicas pode ser explicada com base na legislação do Ensino Superior, uma vez que a obrigatoriedade da indissociabilidade entre ensino-pesquisa-extensão, espinha dorsal da proposta de Universidade elaborada pelo Sindicato Nacional dos Docentes das Instituições do Ensino Superior (ANDES-SN) e regulamentada pelo artigo 207 da Constituição Federal Brasileira (BRASIL, 1988), em decorrência de uma política pública de caráter neoliberal, logo favorecendo ações do mercado econômico, foi extinta através da reconfiguração da organização acadêmica do Ensino Superior (Universidades, Centros Universitários, Faculdades, Institutos Superiores e Escolares Superiores) e limitação da obrigatoriedade da tríade ensino-pesquisa-extensão das Universidades, o que isentou a obrigatoriedade de 
Junior Vagner P. da Silva, Tatiana C. Farias de Mendonça e Grupos de Pesquisa e Enfoque dado ao Lazer... Tânia Mara Vieira Sampaio

desenvolvimento da pesquisa por Centros Universitários, Faculdades, Institutos Superiores e Escolas Superiores (BRASIL, 1997), condição precarizada ainda mais com a redação do decreto $n^{0} 3.860 / 2001$, que estabelece a obrigatoriedade pela oferta de atividades de ensino, de pesquisa e de extensão apenas às Universidades, desconsiderando a indissociabilidade da tríade ensino-pesquisa-extensão (BRASIL, 2001 ${ }^{\text {b }}$.

Todavia, ainda tomando como parâmetro os ordenamentos legais, a predominância dos estudos em Universidades Públicas também pode estar relacionada ao regime de trabalho diferenciado, pois enquanto nas Instituições Privadas impera o regime de trabalho por horas, uma vez que a legislação vigente exige que apenas um terço do corpo docente atue em regime de tempo integral (BRASIL, 1996, artigo 52), apenas estes 30\% têm a possibilidade de dedicar 20 horas semanais aos estudos, pesquisas, trabalhos de extensão, planejamento e avaliação - Decreto n ${ }^{\circ} 2.207$, artigo $5^{\circ}$, inciso $4^{\circ}$ (BRASIL, 1997), Decreto ${ }^{\circ} 3.860$, artigo $9^{\circ}$ (BRASIL, 2001 ${ }^{\mathrm{b}}$ ) e Decreto $\mathrm{n}^{\mathrm{o}}$ 5.773, artigo 69 $9^{\circ}$, parágrafo único (BRASIL, 2006), as Instituições Públicas por disporem de estatuto jurídico especial, em sua maioria usufruem do regime de trabalho de Dedicação Exclusiva (BRASIL, 1996). Ainda, a predominância de grupos de pesquisa com status jurídico público pode estar relacionada à maior distribuição de bolsas às instituições públicas (86.9\%) quando comparadas com as privadas $(6,1 \%)$ (GEOCAPES, 2013).

Considerando que as Instituições de Ensino Superior privadas são responsáveis pela formação de $70 \%$ dos acadêmicos da graduação (SCHWARTZMAN, 2004) e que a pesquisa se constitui num importante mecanismo de sustentação do ensino, pois “[...] Faz parte do processo de informação, como instrumento essencial para a emancipação. Não só para ter, sobretudo para ser, é mister saber" (DEMO, 2011, p. 16), a baixa existência de grupos de pesquisas nas instituições privadas pode estar contribuindo para um duplo processo de debilidade na formação de nível superior, muito distante da proposição de Demo (2011, p. 15) 
Junior Vagner P. da Silva, Tatiana C. Farias de Mendonça e Grupos de Pesquisa e Enfoque dado ao Lazer... Tânia Mara Vieira Sampaio

ao tratar da práxis histórica do conhecimento, "quem ensina carece pesquisar; quem pesquisa carece ensinar $[\ldots] "$.

Por seu turno, a predominância da divulgação do conhecimento via periódicos pode estar relacionada ao maior alcance que estes veículos têm, uma vez que a maioria dos periódicos está indexada em bases de dados eletrônicos nacionais e internacionais, como WebCapes, Lilacs, Scielo, PubMed, Medline, Scopus, Institute of Scientific Information (ISI), dentre outros, proporcionando maior circulação do conhecimento e acesso livre e irrestrito a um maior número de leitores, possibilitando tanto a incorporação destes conhecimentos em novos estudos quanto a apropriação destes conhecimentos e sua aplicação em experiências práticas.

Todavia, considerando que a maioria dos líderes dos grupos de pesquisas se encontra vinculada a programas de Mestrado, a predominância das publicações em periódicos também pode estar relacionada à visão imposta pela CAPES aos pesquisadores interessados em se credenciarem ou se manterem credenciados em programas de pós-graduação Stricto Sensu, pois cada vez mais este órgão de regulamentação dos Mestrados e Doutorados no país se rende aos fetiches da valorização de artigos em periódicos, pois conforme expõem Rigo, Ribeiro e Hallal (2011), a principal ferramenta de avaliação de produção científica tem sido artigos indexados.

Em relação aos enfoques dados às investigações realizadas pelos grupos, a análise dos objetivos das linhas de pesquisas indica que dentre os específicos predominam estudos sobre políticas públicas, formação profissional, gestão, mídia, espaços e equipamentos de lazer, esporte de aventura e atividade física na natureza, turismo e sustentabilidade. Já entre os não específicos se destacam o interesse por estudos relacionados às políticas públicas, formação profissional, atividade física e saúde, história do esporte e atividade física e qualidade de vida, conforme pode ser visualizado na Figura 2. Ainda, esta análise revela que apenas três grupos 
Junior Vagner P. da Silva, Tatiana C. Farias de Mendonça e Grupos de Pesquisa e Enfoque dado ao Lazer... Tânia Mara Vieira Sampaio

específicos (Núcleo de Motricidade, Desenvolvimento Humano e Lazer/UNIARARASSP/2007, Grupo de Pesquisa em Educação Física e Esportes Adaptados/Universidade Federal Rural do Rio de Janeiro/2011e Turismo, Viagens, Cultura e Lazer: canais de difusão do conhecimento/Instituto Federal da Bahia/2012) e sete não específicos (Núcleo de pesquisas em movimento/Universidade Metodista de Piracicaba/2000, Núcleo Interdisciplinar de Estudos e Pesquisas em Atividade Física e Saúde/Universidade Federal de Uberlândia/2000, Ergonomia e usabilidade de produtos, sistemas e produção/Universidade Federal de Pernambuco/2001, Atividade Física e Deficiência Mental/Universidade de Brasília/2002, História da Cultura Corporal, Educação, Esporte, Lazer e sociedade/Universidade Federal da Bahia/2004, Grupo de Estudos e Pesquisas em Educação Física, Esporte e Lazer/Universidade 
Junior Vagner P. da Silva, Tatiana C. Farias de Mendonça e Grupos de Pesquisa e Enfoque dado ao Lazer...

Tânia Mara Vieira Sampaio

Figura 2. Temáticas abordadas pelas linhas de pesquisas analisadas

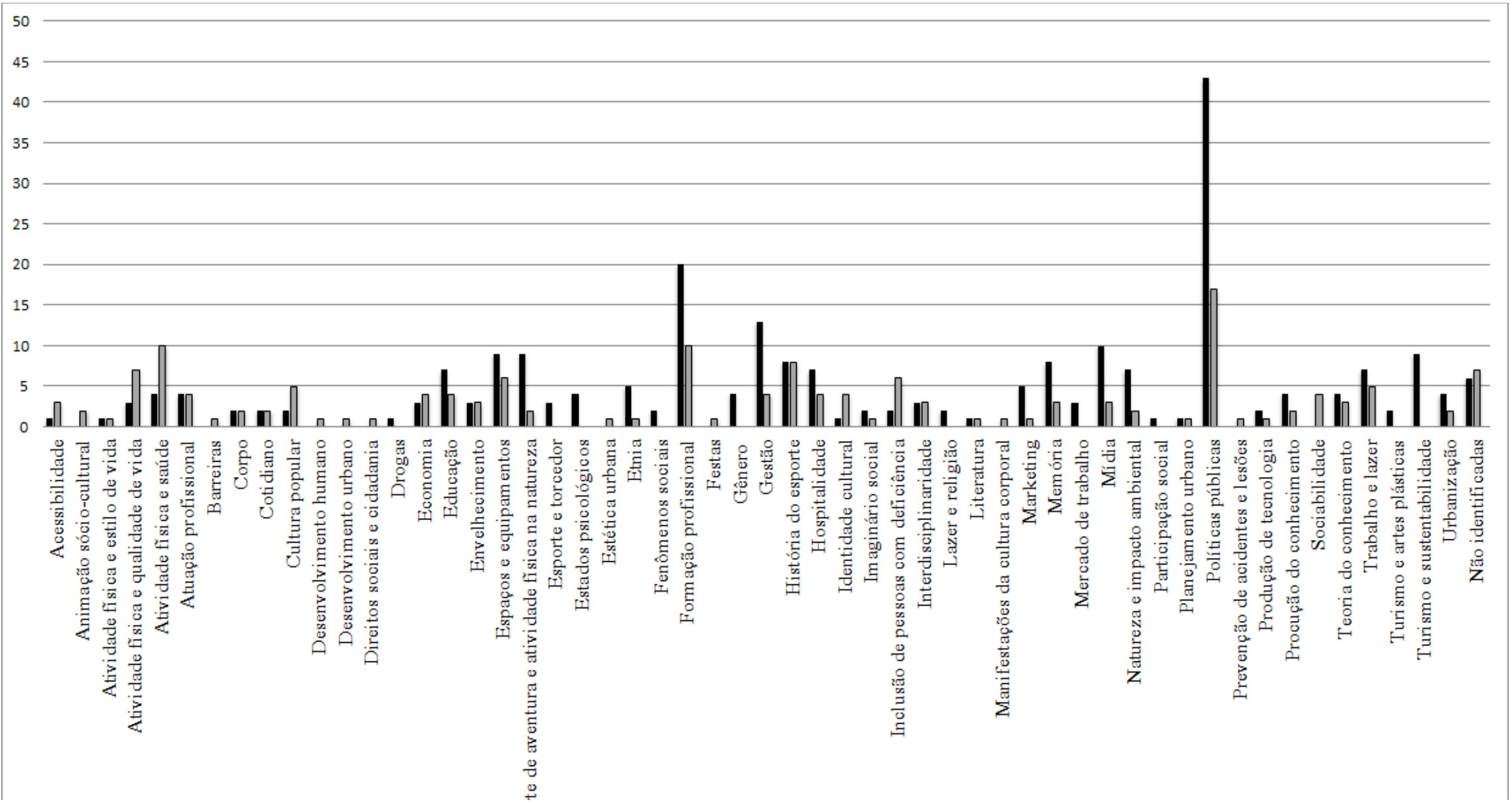


Junior Vagner P. da Silva, Tatiana C. Farias de Mendonça e Grupos de Pesquisa e Enfoque dado ao Lazer... Tânia Mara Vieira Sampaio

do Estado da Bahia/2007 e Núcleo de Estudos e Pesquisas das Dimensões Educativas da Educação Física/Universidade Federal de São Carlos/2008) têm pelo menos uma de suas linhas de pesquisas com objetivos voltados ao desenvolvimento de estudos relacionados ao lazer das pessoas com deficiência.

Por conseguinte, a baixa quantidade de grupos com linhas de pesquisas voltadas aos estudos relacionados ao lazer das pessoas com deficiência demonstra refletir nas publicações dos líderes dos grupos, pois conforme indica a Tabela 3, dos artigos publicados em periódicos apenas $0,8 \%$ e 3,5\%, respectivamente grupos específicos e não específicos, são relacionados ao lazer desta população; condição similar também evidenciada nas publicações em livros e capítulos de livros, orientações de iniciação científica, mestrado e doutorado.

Tabela 3. Frequência absoluta das produções científicas e orientações dos líderes dos grupos de pesquisas

\begin{tabular}{lc|c}
\hline & \multicolumn{2}{c}{ Tipos de grupos } \\
\hline & $\begin{array}{c}\text { Grupos de pesquisa } \\
\text { específicos do lazer }\end{array}$ & $\begin{array}{c}\text { Grupos de pesquisa não } \\
\text { específicos do lazer }\end{array}$ \\
\hline PRODUÇÃO CIENTÍFICA & 1.666 & 2.118 \\
Artigos em periódicos & 700 & 195 \\
Específicos sobre o lazer & 6 & 7 \\
Específicos sobre o lazer de pessoas com deficiência & 1.453 & 1.078 \\
Livros e capítulos de livros & 870 & 131 \\
Específicos sobre o lazer & 4 & 5 \\
Específicos sobre o lazer de pessoas com deficiência & & \\
ORIENTAÇÕES & 599 & 816 \\
Iniciação Científica & 361 & 135 \\
Específicas sobre o lazer & 5 & 2 \\
Específicas sobre o lazer de pessoas com deficiência & 582 & 853 \\
Mestrado & 308 & 4 \\
Específicas sobre o lazer & 6 & 170 \\
Específicas sobre o lazer de pessoas com deficiência & 132 & 20 \\
Teses & 67 & 1 \\
Específicas sobre o lazer & 2 & \\
Específicas sobre o lazer de pessoas com deficiência & &
\end{tabular}

O inexpressível enfoque dado aos estudos relacionados ao lazer das pessoas com deficiência também é observado ao analisar as dez temáticas mais trabalhadas pelos líderes em suas publicações e orientações, pois conforme pode ser visualizado nas Tabelas 4 e 5, 
Junior Vagner P. da Silva, Tatiana C. Farias de Mendonça e Grupos de Pesquisa e Enfoque dado ao Lazer... Tânia Mara Vieira Sampaio

nenhum deles se refere ao lazer desta população. As poucas temáticas encontradas nas publicações dos líderes de grupos específicos foram - periódicos - esporte/atividade física adaptada (4), acessibilidade arquitetônica (2); capítulos de livros - acessibilidade arquitetônica (3); e, entre os líderes de grupos não específicos - periódicos - paralimpismo (1), escolinha esportiva para crianças com deficiência (2), atividade física adaptada para crianças com síndrome de down (1) e com deficiência mental (1), acessibilidade arquitetônica (1) e gestão de políticas públicas para pessoas com deficiência -; capítulos de livros atividade física adaptada (1), dança em cadeiras de rodas (2) e políticas públicas e pessoas com deficiência.

Tabela 4. Temáticas mais abordadas pelos líderes dos grupos de pesquisas em suas publicações

\begin{tabular}{|c|c|c|c|c|c|c|}
\hline & \multicolumn{3}{|c|}{$\begin{array}{l}\text { Publicações dos grupos } \\
\text { específicos }\end{array}$} & \multicolumn{3}{|c|}{$\begin{array}{l}\text { Publicações dos grupos não } \\
\text { específicos }\end{array}$} \\
\hline & Artigos & Livros & $\begin{array}{l}\text { Capítulos } \\
\text { de livros }\end{array}$ & Artigos & Livros & $\begin{array}{l}\text { Capítulos } \\
\text { de livros }\end{array}$ \\
\hline $\begin{array}{l}\text { Esporte de aventura e atividade física na } \\
\text { natureza }\end{array}$ & 55 & 9 & 35 & 8 & - & - \\
\hline Políticas públicas & 53 & 34 & 54 & 27 & 4 & 16 \\
\hline Teoria do conhecimento & 36 & 22 & 22 & - & - & - \\
\hline Mídia & 38 & - & - & - & 2 & - \\
\hline História & 33 & 10 & 25 & - & - & - \\
\hline Espaços e equipamentos & 27 & - & - & 22 & - & - \\
\hline Formação profissional & 26 & - & 29 & - & - & - \\
\hline Trabalho & 25 & - & - & 11 & - & - \\
\hline Animação sociocultural & 22 & - & 36 & - & - & - \\
\hline Atuação profissional & - & 11 & - & - & - & - \\
\hline Educação & - & 40 & 19 & - & 4 & 5 \\
\hline Repertório de jogos & - & 20 & - & - & - & - \\
\hline Humanização & - & 9 & & - & - & - \\
\hline Indústria cultural & - & - & 27 & 7 & - & - \\
\hline Projetos sociais & - & - & 24 & - & - & - \\
\hline Barreiras à prática de atividade física & - & - & - & 18 & - & - \\
\hline Hábitos de lazer & - & - & - & 10 & - & 8 \\
\hline Festas populares & - & - & - & 8 & - & 5 \\
\hline Representação social & - & - & - & - & 2 & - \\
\hline Esporte & - & - & - & - & 2 & - \\
\hline Estilo de vida & - & - & - & - & - & 6 \\
\hline Envelhecimento & - & - & - & - & - & 5 \\
\hline Atividade física e saúde & - & - & - & - & - & 5 \\
\hline
\end{tabular}

deficiência, entre os grupos específicos, foi observado apenas cinco trabalhos de - iniciação 
Junior Vagner P. da Silva, Tatiana C. Farias de Mendonça e Grupos de Pesquisa e Enfoque dado ao Lazer... Tânia Mara Vieira Sampaio

científica - acessibilidade arquitetônica (2), acessibilidade em websites (1) e esporte radical para deficientes (1), três dissertações de mestrado - acessibilidade arquitetônica (3) e uma tese de doutorado - deficiente mental e educação para e pelo lazer (1). Entre os grupos não específicos, foram encontrados dois trabalhos de iniciação científica - acessibilidade arquitetônica em hotéis (1) e dança em cadeiras de rodas (1), quatro dissertações de mestrado - acessibilidade em website (1), esporte/atividade física adaptada para pessoas com síndrome de down (1) e pessoas com deficiência visual (2) e inclusão de pessoas com deficiência no turismo e uma tese de doutorado gestão de atividades físicas para pessoas com deficiência (1).

Tabela 5. Temáticas mais abordadas pelos líderes dos grupos de pesquisas em suas orientações

\begin{tabular}{l|c|c|c|c|c|c}
\hline & \multicolumn{3}{c|}{$\begin{array}{c}\text { Publicações dos grupos } \\
\text { específicos }\end{array}$} & \multicolumn{3}{c}{ Publicações dos grupos não } \\
\hline & I.C. & Dissertações & Tese & I.C. & Dissertaçoses & Teses \\
\hline Esporte de aventura e atividade física na & 23 & 17 & 4 & 15 & - & - \\
natureza & & & & & & \\
Políticas públicas & 14 & 28 & 15 & 9 & 17 & 7 \\
Teoria do conhecimento & 14 & - & - & - & - & - \\
Mídia & 20 & 15 & 3 & - & - & - \\
História & - & 11 & 3 & - & - & - \\
Espaços e equipamentos & 33 & 16 & - & 9 & - & - \\
Formação profissional & 17 & 21 & 7 & - & - & - \\
Animação sociocultural & - & 12 & - & - & - & - \\
Atuação profissional & - & 8 & - & - & - & - \\
Educação & - & - & 5 & - & 8 & - \\
Indústria cultural & - & - & - & - & 3 & - \\
Megaeventos & 15 & - & - & - & - & - \\
Gênero & - & 11 & - & - & - & - \\
Torcida & - & 9 & - & - & - & - \\
Amadorismo & - & - & 5 & - & - & - \\
Memória & 15 & - & - & 5 & - & - \\
Turismo comunitário & 11 & - & - & - & - & - \\
Sustentabilidade & 12 & - & - & 7 & - & - \\
Hábitos de lazer & - & - & - & 9 & 5 & 4 \\
Museu & - & - & - & - & 5 & - \\
Envelhecimento & - & - & - & - & 3 & - \\
Atividade física e saúde & - & - & - & - & - & 3 \\
Barreiras à prática de atividade física & - & - & - & - & - & 3 \\
Legado esportivo & - & - & - & 6 & - & - \\
Esporte & - & - & - & 6 & - & - \\
Festas populares & - & - & - & 9 & - & - \\
Jogos tradicionais & - & - & - & 10 & - & - \\
\hline
\end{tabular}


Junior Vagner P. da Silva, Tatiana C. Farias de Mendonça e Grupos de Pesquisa e Enfoque dado ao Lazer... Tânia Mara Vieira Sampaio

Embora não tenham sido desenvolvidos com objetivos de identificar as temáticas relacionadas ao lazer de pessoas com deficiência, achados de estudos anteriores, como os de Peixoto (2007) e Castro et al. (2012), corroboram com os dados obtidos nesta investigação, haja vista que em ambos nenhuma temática relacionada ao lazer das pessoas com deficiência foi identificada.

Esta condição é preocupante, uma vez que embora avanços tenham ocorrido no cenário internacional e nacional, em que pelo menos no âmbito legal o lazer é assegurado como direito, poucos pesquisadores ligados aos estudos do lazer têm se atentado à importância deste componente social na vida desta população. A baixa quantidade de pesquisadores que se dedicam ao desenvolvimento de estudos relacionados ao lazer das pessoas com deficiência pode contribuir para que se desconheça como esses sujeitos, representante de $23,9 \%$ da população brasileira (INSTITUTO BRASILEIRO DE GEOGRÁFIA E ESTATÍSTICA, 2010), usufrui seu tempo disponível no lazer.

O inexpressível interesse em investigações relacionadas às questões do lazer das pessoas com deficiência observado neste estudo deve ser visto com preocupação, uma vez que a baixa quantidade de estudos dificulta o entendimento de como o Poder Público (Estado), concebido por Souza (2006) como produtor por excelência de políticas públicas, tem se comportado em relação à formulação e implantação de políticas direcionadas ao atendimento deste público.

A importância da produção científica para as políticas públicas, sobretudo os estudos descritivos e exploratórios, se dá em decorrência das pesquisas descritivas possibilitarem a avaliação do atendimento dos órgãos públicos à comunidade (GIL, 2010) e pelos estudos exploratórios permitirem a descoberta de práticas que necessitam ser modificadas, como também viabilizarem a formulação de alternativas que possam substituí-las (OLIVEIRA, 2002), podendo assim influenciar as políticas públicas, dentre elas, as de lazer, haja vista que, 
Junior Vagner P. da Silva, Tatiana C. Farias de Mendonça e Grupos de Pesquisa e Enfoque dado ao Lazer... Tânia Mara Vieira Sampaio

embora pesquisadores não atuem na formulação de Políticas Públicas, estes podem exercer grande influência na criação de alternativas, propostas e soluções para um dado problema (KINGDON, 2006; CAPELA, 2010).

Ainda, torna-se importante ter clareza que a ausência de estudos relacionados ao lazer das pessoas com deficiência também pode trazer prejuízos à formação e atuação profissional com animação sociocultural voltada a essa população, pois considerando que é a pesquisa que alimenta e atualiza o ensino (MINAYO, 1994), as discussões sobre o assunto correm o risco de ficarem limitadas ou desprovidas de dados empíricos e reflexão teórica sobre a temática.

Por outro lado, o desenvolvimento de estudos com enfoque no lazer das pessoas com deficiência pode favorecer a criação de alternativas em prol de políticas públicas voltadas à essa população, fortalecendo a ampliação das oportunidades e sua inserção em ocasiões sociais, como o lazer, condição que se faz de suma importância para que se viva a vida em sua plenitude.

Segundo Blascovi-Assis (2003), por vezes, as pessoas com deficiência têm suas oportunidades de lazer restringidas devido a barreiras sociais. Ou seja, considerando que além de se manifestar como mecanismo duplamente educativo, uma vez que o acesso aos seis interesses culturais pode agir como veículo de educação para o lazer (estimular a população a usufruir do tempo disponível com oportunidades de lazer) e que ao terem acesso a essas oportunidades, podem ser estimuladas a agir em níveis críticos e criativos (educação pelo lazer) (MARCELLINO, 2003).

No caso das pessoas como deficiência, a exemplo do que já vem ocorrendo com a dimensão do trabalho e da educação, o acesso ao lazer também significa inserção social e processo formativo para o convívio em comunidade, onde se aprenda a conhecer, reconhecer e viver com as diferenças humanas. 
Junior Vagner P. da Silva, Tatiana C. Farias de Mendonça e Grupos de Pesquisa e Enfoque dado ao Lazer... Tânia Mara Vieira Sampaio

Finalizando, entendemos que as informações obtidas e as reflexões desenvolvidas ao longo deste trabalho auxiliam-nos a melhor compreender o "estado da arte" na produção de conhecimento sobre o lazer e a inclusão das pessoas com deficiência, demonstrando que este campo de estudos tem sido negligenciado e não tem recebido a atenção dos líderes das pesquisas analisadas, ou seja, revela-se como um campo carente de investigações, provocando lacunas no conhecimento e mostrando uma área de atuação que demanda o desenvolvimento de estudos.

\section{REFERÊNCIAS}

ALVES, C. et al. Lazer e políticas públicas no setor governamental - análise da revista Licere. Revista Brasileira Ciências e Movimento, v. 19, n. 2, p. 78-89, 2011.

ALVES, C. et al. Lazer, políticas públicas não governamentais e estudos conceituais, na Revista Licere. Revista de Educação Física/UEM, v. 23, n. 2, p. 239-249, 2012.

AMARAL, S. C. F.; PEREIRA, A. P. C. Reflexões sobre a produção em políticas públicas de educação física, esporte e lazer. Revista Brasileira de Ciência e Esporte, v. 31, n. 1, p. 41$56,2009$.

BARDIN, L. Análise de Conteúdo. Lisboa: Edições 70 LDA, 2009.

BLASCOVI-ASSIS, S. M. Lazer para deficientes mentais. In: MARCELLINO, N. C. Lúdico, educação e educação física. 2. ed. Ijuí: Unijuí, 2003. p. 101-111.

BORGES, L. J. et al. Grupos de pesquisa sobre atividade física e envelhecimento no Brasil. Revista Brasileira de Atividade Física e Saúde, v. 17, n. 2, p. 114-120, 2012.

BRASIL. Constituição (1988). Constituição da República Federativa do Brasil, 1988. Brasília: Senado Federal, Centro Gráfico, 1988.

BRASIL. Decreto n. 2.207 de 15 de abril de 1997. Presidência da República. Brasília - DF: Casa Civil, 1997. Disponível em: http://www.planalto.gov.br/ccivil_03/decreto/D2207.htm Acesso: 16 jan. 2013.

BRASIL. Decreto n. 3.860 de 9 de julho de 2001. Presidência da República. Brasília - DF: Casa Civil, 2001 $1^{\mathrm{b}}$.http://www.planalto.gov.br/ccivil_03/decreto/2001/D3860.htm. Acesso em: 16 jan. 2013.

BRASIL. Decreto n. 5.773 de 9 de maio de 2006. Presidência da República. Brasília - DF. Casa Civil, 2006. Disponível em: http://www.planalto.gov.br/ccivil 03/Ato20042006/2006/Decreto/D5773.htm\#art79. Acesso: 16 jan. 2013. 
Junior Vagner P. da Silva, Tatiana C. Farias de Mendonça e Grupos de Pesquisa e Enfoque dado ao Lazer... Tânia Mara Vieira Sampaio

BRASIL. Lei n. 9.394/96 de 20 de dezembro de 1996. Presidência da República. Brasília DF: Casa Civil, 1996. Disponível em: http://www.planalto.gov.br/ccivil_03/Leis/L9394.htm. Acesso: 16 jan. 2013.

BRASIL. Lei n. 9.478 de 6 de Agosto de 1997. Presidência da República. Brasília - DF: Casa Civil, 1997. Disponível: http://www.planalto.gov.br/ccivil 03/leis/19478.htm Acesso: 29 mar. 2013.

BRASIL. Lei n. 10.197 de 14 de fevereiro de 2001. Presidência da República. Brasília - DF: Brasília - DF: Casa Civil, 2001 ${ }^{\mathrm{a}}$ Disponível em: http://www.planalto.gov.br/ccivil_03/Leis/LEIS_2001/L10197.htm. Acesso: 02 jan. 2013.

BRASIL. Portaria n 179 de 20 de Outubro de 2011. Chamada Pública para submissão projetos de pesquisa a serem desenvolvidos na REDE CEDES - Centros de Desenvolvimento do Esporte e do Lazer. Brasília - DF. Diário Oficial da União, n ${ }^{0}$ 203, 2011 ${ }^{\mathrm{a}}$, p. 166. Disponível em: http://www.in.gov.br/imprensa/visualiza/index.jsp?.jornal=1\&pagina=166\&data=21/10/2011. Acesso: 15 jun. 2012.

BRASIL. Portaria n. 219 de 23 de dezembro de 2011. Diário Oficial da União, $\mathrm{n}^{0} 247$, 2011 , p. 303. Disponível em:

http://www.esporte.gov.br/arquivos/snelis/esporteLazer/cedes/portariaN21923122011RedeCe des.pdf>. Acesso: 15 jun. 2012.

CAPELlA, A. C. N. Perspectivas teóricas sobre o processo de formulação de políticas públicas. In: HOCHMAN, G.; ARRETCHE, M.; MARQUES, E. Políticas públicas no Brasil. 2. ed. Rio de Janeiro: Editora Fiocruz, 2010. p. 87-122.

CAPES. Propostas aprovadas no Edital Capes no 6/2012 - Programa Professor Visitante Nacional Sênior. Brasília - DF: CAPES, 2012 $2^{\mathrm{b}}$ Disponível em: http://www.capes.gov.br/images/stories/download/editais/resultados/ResultadoPVNS2012.pdf >. Acesso em: 25 de março 2013.

CAPES. Edital n. 24/2012 - Pró-equipamentos institucional 2012 - propostas aprovadas. Brasília - DF: CAPES, 2012 ${ }^{\mathrm{a}}$ Disponível em: http://www.capes.gov.br/images/stories/download/editais/resultados/ResultadoProEquipamen tos-Edital-24-2012.pdf>. Acesso em: 25 de março de 2013.

CASTRO, S. B. E. et al. O estado da arte em políticas sociais de esporte e lazer no Brasil (2000-2009). Pensar a prática, v. 15, n. 2, p. 531-545, 2012.

CNPq. Chamada MCTI/CNPq/FINEP No 06/2012 - ARC. Conselho Nacional de Pesquisa. Disponível em: http://www.cnpq.br/web/guest/chamadaspublicas?p_p_id=resultadosportlet_WAR_resultadoscnpqportlet INSTANCE_0ZaM\&filtro $=r$ esultados\&detalha $=$ chamadaDetalhada\&exibe $=$ exibe\&idResultado=434-1-1605\&id $=434-1$ 1605>. Acesso em: 15 mar. 2013.

DEMO, P. Pesquisa: princípio científico e educativo. 14. ed. São Paulo: Cortez, 2011.

DESLANDES, S. F. A construção do projeto de pesquisa. In: MINAYO, M. C. de; et al. (Org.). Pesquisa social: teoria, método e criatividade. Petrópolis: Vozes, 1994. 
Junior Vagner P. da Silva, Tatiana C. Farias de Mendonça e Grupos de Pesquisa e Enfoque dado ao Lazer... Tânia Mara Vieira Sampaio

DUCA, G. F. D.; et al. Grupos de pesquisa em cursos de Educação Física com pós-graduação "stricto sensu" no Brasil: análise temporal de 2000 a 2008. Rev. Bras. Educ. Fís. Esporte, v. 25, n. 4, p. 607-617, 2011.

FERREIRA, R. A.; SILVA, C. L. Formação profissional em lazer: produção acadêmica no período de 2005 a 2009. Licere, v. 15, n. 3, p. 1-38, 2012.

GEOCAPES. Dados Estatísticos. Disponível em: http://geocapes.capes.gov.br/geocapesds/. Acesso em: 02 fev. 2013.

GIL, A. C. Métodos e técnicas de pesquisa social. 6. ed. São Paulo: Atlas, 2010.

GOMES, C. L.; MELO, V. A. Lazer no Brasil: trajetória de estudos, possibilidades de pesquisas. Movimento, v. 9, n. 3, p. 23-44, 2003.

INSTITUTO BRASILEIRO DE GEOGRÁFIA E ESTATÍSTICA. Censo demográfico características gerais da população, religião e pessoas com deficiência. Rio de Janeiro: IBGE, 2010 .

ISAYAMA, H. F. Atuação do profissional de educação física no âmbito do lazer: a perspectiva da animação cultural. Revista Motriz, v. 15, n. 2, p. 407-413, 2009.

KINGDON, J. Juntando as coisas. In: SARAVIA, E.; FERRAREZI, E. (Org.). Políticas públicas; coletânea. Brasília: ENAP, 2006. p. 225-245.

MARCASSA, L. A invenção do lazer: educação, cultura e tempo livre na cidade de São Paulo (1888-1935). 2002. 213 f. Dissertação (Mestrado) - Faculdade de Educação, Universidade Federal de Goiás, Goiás, 2002.

MARCELLINO, N. C. Lazer e educação. 10. ed. Campinas: Papirus, 2003.

MARCELLINO, N. C. Políticas de lazer. Mercadores ou educadores? Os cínicos bobos da corte. In: MARCELLINO, N. C. (Org.). Políticas públicas de lazer. Campinas: Editora Alínea, 2008. p. 21-41.

MARCELLINO, N. C. et al. Análise qualitativa dos trabalhos relacionados à temática "lazer e políticas públicas", publicados nos anais do Enarel, de 1991 a 2008. Licere, v. 12, n. 4, p. 125, 2009.

MARINHO, A. et al. Grupo de pesquisa em lazer e intercâmbios internacionais. Licere, v. 14, n. 3, p. 1-21, 2011.

MELO, V. A. de; ALVES JÚNIOR, E. de D. Introdução ao lazer. Barueri: Manolé, 2003.

MINAYO, M. C. de S. Ciência, técnica e arte: o desafio da pesquisa social. In: MINAYO, M. C. de S.; et al. (Org.). Pesquisa social: teoria, método e criatividade. Petrópolis: Vozes, 1994. p. 9-29.

MINAYO, M. C. de S. O desafio do conhecimento. Pesquisa qualitativa em saúde. 8. ed. São Paulo: Hucited, 2004. 
Junior Vagner P. da Silva, Tatiana C. Farias de Mendonça e Grupos de Pesquisa e Enfoque dado ao Lazer... Tânia Mara Vieira Sampaio

MUGNAINI, R.; JANNUZZI, P. de M.; QUONIAM, L. Indicadores bibliométricos da produção científica brasileira: uma análise a partir da base Pascal. Ci. Inf., v. 33, n. 2, p. 123 $131,2004$.

MUNSTER, M. de A. V.; ROSSI, P.; FERREIRA, E. F. Diretório dos Grupos de Pesquisa do CNPq: Análise da Produção Científica em Atividade Física Adaptada. Revista da Sociedade Brasileira de Atividade Motora Adaptada, v. 13, p. 18-24, 2012.

OLIVEIRA, S. L. Tratado de metodologia científica. 2. ed. São Paulo: Pioneira, 2002.

PADILHA, V. Introdução. In: PADILHA, V. (Org.). Dialética do lazer. São Paulo: Cortez, 2006. p. 4-10.

PEIXOTO, E. M. M. Levantamento do Estado da arte nos estudos do lazer: (Brasil) séculos XX e XXI - alguns apontamentos. Educ Soc, v. 28, n. 99, p. 561-586, 2007.

Os estudos do lazer no Brasil - apropriação da obra de Marx e Engels. Movimento, v. 14, n. 3, p. 87-116, 2008.

; PEREIRA, Maria de Fátima Rodrigues. Primeiro ciclo dos estudos do lazer no Brasil: contexto histórico, temáticas e problemáticas. Movimento, v. 16, n. 2, p. 267-288, 2010.

PINTO, L. M. S. de M. A recreação/lazer e a educação física: a manobra da autenticidade do jogo. 1992. 127 f. Dissertação (Mestrado) - Escola de Educação Física de Campinas, Campinas, 1992.

RIGO, L. C.; RIBEIRO, G. M.; HALLAL, P. H. Unidade na diversidade: desafios para a Educação Física no Século XXI. Revista Brasileira de Atividade Física e Saúde, v. 16, n. 4, p. 339-345, 2011.

SANTOS, A.; et al. Distribuição, evolução e produção científica dos grupos de pesquisa em atividade física e saúde do Brasil. Rev Bras Ativ Fis e Saúde, v. 17, n. 4, p. 258-262, 2012.

SCHAWARTZMAN, S. Educação: a nova geração de reformas: In: GIAMBIAGI, F.; REIS, J. G.; URANI, A. (Org.). Reformas no Brasil: balanço e agenda. Rio de Janeiro: Nova Fronteira, 2004. p. 481-504.

SOUZA, C. Políticas públicas: uma revisão da literatura. Sociologias, v. 8, n. 16, p. 20-45, 2006.

STEINER, João. Qualidade e diversidade institucional na pós-graduação brasileira. Estudos avançados, v. 19, n. 54, p. 341-365, 2005.

STOPPA, E. A.; et al. A produção do conhecimento na área do lazer - uma análise sobre os anais do ENAREL de 1997 a 2006 - formação e atuação profissional. Licere, v. 13, n. 2, p. 1$22,2010$.

ZORZETTO, R. et al. The scientific production in health and biological sciences of the top 20 Brazilian universities. Braz J Med Bial Res, v. 39, n. 12, p. 1513-1520, 2006. 
Junior Vagner P. da Silva, Tatiana C. Farias de Mendonça e Grupos de Pesquisa e Enfoque dado ao Lazer... Tânia Mara Vieira Sampaio

\section{Endereço dos Autores:}

Junior Vagner Pereira da Silva Universidade Federal do Mato Grosso do Sul

Campus Soane Nazaré de Andrade, Rodovia Jorge Amado, Km 16, Bairro Salobrinho Ilhéus - BA - CEP 45662-900

Endereço Eletrônico: jr_lazer@yahoo.com.br

Tattiana Côrtes Farias de Mendonça

Universidade Estadual de Santa Cruz - UESC

Campus Soane Nazaré de Andrade, Rodovia Jorge Amado, Km 16, Bairro Salobrinho Ilhéus - BA - CEP 45662-900

Endereço Eletrônico: jr_lazer@yahoo.com.br

Tânia Mara Vieira Sampaio

Universidade Católica de Brasília - UCB

QS 07 Lote 01 EPCT - Bloco G Sala G 119 - Águas Claras

Taguatinga - DF - 71966-700

Endereço Eletrônico: tsampaio@ucb.br 